\title{
Removal of strontium from aqueous solutions using scallop shell powder
}

\author{
Fumihiro MIHARA ${ }^{1}$, Yuta SHUSEKI ${ }^{1}$, Sanae TAMURA ${ }^{2}$, Koichi UI $^{3}$, Kenta KIKUCHI ${ }^{4}$, \\ Atsuo YASUMORI ${ }^{5}$, Shinichi KOMABA ${ }^{6}$, Mika FUKUNISHI ${ }^{6}$, Yasuo KOGo ${ }^{5}$, \\ Yasushi IDEMOTO $^{1}$ and Ken TAKEUCHI ${ }^{1,2, \uparrow}$ \\ ${ }^{1}$ Department of Pure and Applied Chemistry, Faculty of Science and Technology, Tokyo University of Science, \\ 2641 Yamazaki, Noda, Chiba 278-8510, Japan \\ ${ }^{2}$ Liberal Arts in Oshamambe, Faculty of Industrial Science and Technology, Tokyo University of Science, \\ 102-1 Tomino, Oshamambe-cho, Hokkaido 049-3514, Japan \\ ${ }^{3}$ Department of Chemistry and Biological Sciences, Faculty of Science and Engineering, Iwate University, \\ 4-3-5 Ueda, Morioka 020-8551, Japan \\ ${ }^{4}$ Frontier Materials and Function Engineering, Graduate School of Engineering, Iwate University, \\ 4-3-5 Ueda, Morioka 020-8551, Japan \\ ${ }^{5}$ Department of Materials Science and Technology, Faculty of Industrial Science and Technology, Tokyo University of Science, \\ 6-3-1 Niijyuku, Katsushika-ku, Tokyo 125-8585, Japan \\ ${ }^{6}$ Department of Applied Chemistry, Faculty of Science, Tokyo University of Science, \\ 12-1 Funagawara-cho, Ichigaya, Shinjuku-ku, Tokyo 162-0826, Japan
}

It is important to efficiently remove radioactive substances contained in polluted waters before they are discharged from nuclear power plants. In particular, there is an urgent need for the development of technology that can adsorb radioactive $\mathrm{Sr}^{2+}$, but there are currently no inexpensive $\mathrm{Sr}^{2+}$ adsorbents with low environmental burden. We found that scallop shell powder adsorbs $\mathrm{Sr}^{2+}$ in aqueous solutions at various initial concentrations. In this study, to obtain fundamental knowledge of the mechanism of $\mathrm{Sr}^{2+}$ removal using waste scallop shell, we analyzed the removability of $\mathrm{Sr}^{2+}$. Scallop shell showed the same capacity to remove $\mathrm{Sr}^{2+}$ at a high initial concentration $\left(\geq 0.50 \mathrm{~g} / \mathrm{dm}^{3}\right)$ as the reagent $\mathrm{CaCO}_{3}$, but a clear difference in removability appeared at a low initial concentration $\left(0.010 \mathrm{~g} / \mathrm{dm}^{3}\right)$, where scallop shell proved to be superior. In addition, scallop shell powder had slit-shaped pores and a specific surface area of $4.3 \mathrm{~m}^{2} / \mathrm{g}$. Measurement of the adsorption isotherm in the low concentration aqueous solution showed that $\mathrm{Sr}^{2+}$ removal occurred by chemisorption; the adsorbed $\mathrm{Sr}$ is present on the surface of the scallop shell powder particles.

(202019 The Ceramic Society of Japan. All rights reserved.

Key-words : Scallop shell, Adsorption, Strontium, Calcium carbonate, Radioactive elements, Water treatment

[Received August 17, 2018; Accepted November 20, 2018]

\section{Introduction}

Processing of the $\sim 1$ million tons of contaminated water currently accumulated around the Fukushima Daiichi Nuclear Power Plant has stagnated. ${ }^{1)}$ The efficient removal of radioactive substances such as $\mathrm{Cs}^{+}$and $\mathrm{Sr}^{2+}$ are necessary for processing to proceed. Residual $\mathrm{Sr}^{2+}$ is particularly dangerous to the human body due to its propensity to replace $\mathrm{Ca}^{2+}$ in bones. Studies have attempted $\mathrm{Sr}^{2+}$ removal from aqueous solutions by $\mathrm{Sr}^{2+}$ adsorption using antimony oxide, ${ }^{2)}$ tantalum-doped tungsten oxide, ${ }^{3)}$ and layered potassium titanate. ${ }^{4)}$ However, since these adsorbent materials use rare metals, they involve high manu-

Corresponding author: K. Takeuchi; E-mail: ken@rs.kagu. tus.ac.jp facturing costs and are not suitable for the treatment of large amounts of contaminated water; thus, these methods have not been put to practical use. Hence, in order to treat contaminated water, there is still an urgent need to develop an inexpensive adsorbent with low environmental burden.

One potential adsorbent is recycled scallop shell, which has been utilized previously as a removal agent for harmful substances; for example, as an aldehyde remover, ${ }^{5)-7)}$ volatile organic compounds adsorbent, ${ }^{5), 6), 8)}$ desulfurization material, ${ }^{9), 10)}$ and dephosphorization material. ${ }^{11)}$ It is expected that waste scallop shells, which are currently discarded, can be utilized as raw materials for inexpensive and environmentally friendly agents that remove harmful substances. From this perspective, aim to apply scallop shells for the treatment of contaminated water generated from nuclear power plants. While scallop shell powder 
removes $\mathrm{Sr}^{2+}$ from aqueous solutions, we are yet to elucidate the mechanism by which the powder removes $\mathrm{Sr}^{2+}$. In this report, we attempt to elucidate basic knowledge as to mechanism the of $\mathrm{Sr}^{2+}$ removal by scallop shell powder.

\section{Experimental procedures}

\subsection{Preparation of scallop shell powder}

The meat of the scallops was removed from the shells, which were then cleaned to remove any dirt or stains, then air dried at room temperature. The shells $(60 \mathrm{~g})$ were crushed for $3 \mathrm{~h}$ with a stamp mill (NITTO KAGAKU, ANS-143) and a further $3 \mathrm{~h}$ with an automatic mortar (NITTO KAGAKU, AMM-140D). We then analyzed the $\mathrm{Sr}^{2+}$ removability of the obtained powder. The reagent $\mathrm{CaCO}_{3}$ was used for comparison (Kishida Chemical, Special Grade).

\subsection{Evaluation of $\mathrm{Sr}^{2+}$ removability}

$\mathrm{SrCl}_{2} \cdot 6 \mathrm{H}_{2} \mathrm{O}$ hydrate (Kishida Chemical, Special Grade) was dissolved in ion exchanged water to prepare a $\mathrm{SrCl}_{2}$ aqueous solution of a known concentration. The $\mathrm{SrCl}_{2}$ aqueous solution was stirred, and $3.0 \mathrm{~g}$ of scallop shell powder or regent $\mathrm{CaCO}_{3}$ powder were added, such that the powder concentration was $60 \mathrm{~g} / \mathrm{dm}^{3}$. After a certain period of time, the aqueous solution was sampled using a syringe with a filter (Advantec, pore size $0.20 \mu \mathrm{m}$ ), and then suitably diluted. Measurements were taken with an atomic absorption spectrometer (AAS; Thermo, iCE 3300) to determine the $\mathrm{Sr}^{2+}$ concentration. The removability of $\mathrm{Sr}^{2+}$ was evaluated by comparing the initial $\mathrm{Sr}^{2+}$ concentration of the aqueous solution to that of the sampled aqueous solution. The $\mathrm{Sr}^{2+}$ removability of each powder was expressed by the $\mathrm{Sr}^{2+}$ residual rate, calculated by $\left(\mathrm{Sr}^{2+}\right.$ concentration in sample aqueous solution $) /\left(\mathrm{Sr}^{2+}\right.$ initial concentration) $\times 100=\mathrm{Sr}^{2+}$ residual rate. Where the $\mathrm{Sr}^{2+}$ initial concentration is the concentration of $\mathrm{Sr}^{2+}$ in aqueous solution prior to adding the powder.

\subsection{Method of evaluating the analysis of scallop shell powder}

Individual identification was performed using X-ray diffractometry (XRD; Rigaku, RINT-2000), and X-ray photoelectron spectroscopy (XPS; PerkinElmer, PHI 5000 VersaProbe). The XRD patterns were obtained at room temperature using $\mathrm{CuK} \alpha$ radiation $(40 \mathrm{kV}$ and $40 \mathrm{~mA})$. Data were collected in the range of $20^{\circ} \leq 2 \theta \leq 50^{\circ}$ in steps of $0.01^{\circ}$. The XPS data were obtained by using characteristic $\mathrm{Al} \mathrm{K} \alpha$ X-ray radiation $(1486.6 \mathrm{eV})$.

The morphology and elemental composition of the solids were analyzed before and after suspension using scanning electron microscopy (SEM; JEOL, JSM-6360A), and time of flight secondary ion mass spectrometry (TOFSIMS; ULVAC-PHI, PHI TRIFT V nanoTOF). In TOFSIMS, the liquid metal ion source consisted of an Au projectile $\left(\mathrm{Au}_{3}{ }^{+}\right)$, and the range of analysis was $100 \times 100$ $\mu \mathrm{m}$. Furthermore, the specific surface area of the powder was determined using a Brunauer-Emmett-Teller (BET) measuring device (MicrotracBEL, BELSORP-mini II).

\section{Results and discussion}

3.1 $\mathrm{Sr}^{2+}$ removability of scallop shell powder The $\mathrm{Sr}^{2+}$ removability of the reagent $\mathrm{CaCO}_{3}$ has been previously reported at an initial $\mathrm{Sr}^{2+}$ concentration of 1.1 $\mathrm{g} / \mathrm{dm}^{3}{ }^{12)}$ Figure 1 shows the $\mathrm{Sr}^{2+}$ removability of both $\mathrm{CaCO}_{3}$ and scallop shell powder at various initial concentrations, after suspending $3.0 \mathrm{~g}$ of powder in $0.050 \mathrm{dm}^{3}$ (concentration of the powder $60 \mathrm{~g} / \mathrm{dm}^{3}$ ) of a $\mathrm{SrCl}_{2}$ aqueous solution for $15 \mathrm{~h}$ at $25^{\circ} \mathrm{C}$.

At an initial concentration of $\geq 0.50 \mathrm{~g} / \mathrm{dm}^{3} \mathrm{Sr}^{2+}$, both scallop shell powder and $\mathrm{CaCO}_{3}$ showed similar $\mathrm{Sr}^{2+}$ removability. However, with an initial concentration $<0.50 \mathrm{~g} / \mathrm{dm}^{3}$, the $\mathrm{Sr}^{2+}$ removability of the scallop shell powder was far higher than that of the reagent $\mathrm{CaCO}_{3}$ : at an initial concentration of $0.010 \mathrm{~g} / \mathrm{dm}^{3}$, the reagent $\mathrm{CaCO}_{3}$ still had a residual $\mathrm{Sr}^{2+}$ rate of almost $100 \%$, whereas the residual $\mathrm{Sr}^{2+}$ concentration in the solution with scallop shell powder was below the detection limit of AAS, indicating the superior removability of the scallop shell powder at low initial concentrations.

Figure 2 shows the change over time of the residual rate of $\mathrm{Sr}^{2+}$ concentration in a high-concentration aqueous solution of $\mathrm{SrCl}_{2}\left(1.1 \mathrm{~g} / \mathrm{dm}^{3} \mathrm{Sr}^{2+}\right)$, to which the powder was suspended. Measurements were taken by adding $30 \mathrm{~g}$

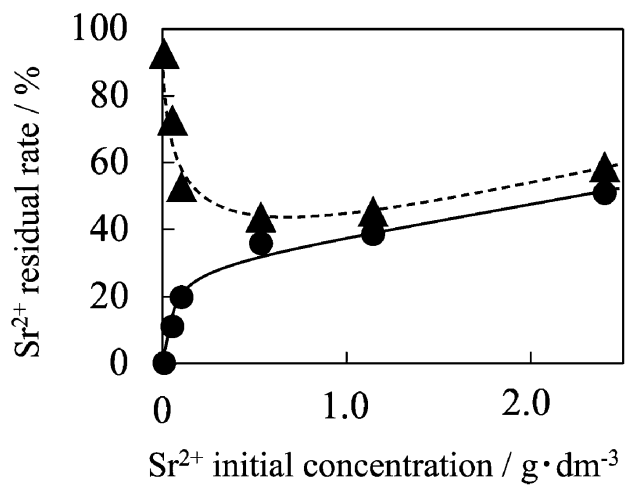

Fig. 1. $\mathrm{Sr}^{2+}$ adsorption capacity depending on $\mathrm{Sr}^{2+}$ initial concentration. ( $\mathbf{\Lambda}$, a dotted line) $\mathrm{CaCO}_{3},(\boldsymbol{O}$, a solid line) scallop shell. Initial concentration of $\mathrm{Sr}^{2+} 0.010$ to $2.4 \mathrm{~g} / \mathrm{dm}^{3}, 25^{\circ} \mathrm{C}$, concentration of the powder $60 \mathrm{~g} / \mathrm{dm}^{3}, 15 \mathrm{~h}$ suspended.

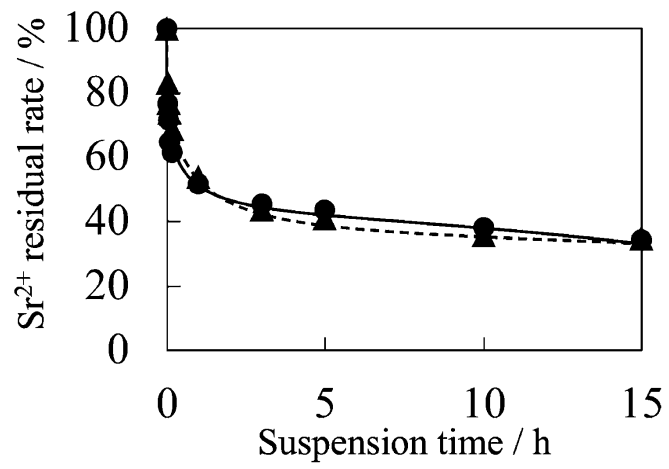

Fig. 2. Change in $\mathrm{Sr}^{2+}$ residual rate over time in suspension. ( $\boldsymbol{\Delta}$, a dotted line) $\mathrm{CaCO}_{3}$ and $(\boldsymbol{O}$, a solid line) scallop shell. Initial concentration of $\mathrm{Sr}^{2+} 1.1 \mathrm{~g} / \mathrm{dm}^{3}, 25^{\circ} \mathrm{C}$, concentration of the powder $60 \mathrm{~g} / \mathrm{dm}^{3}$. 


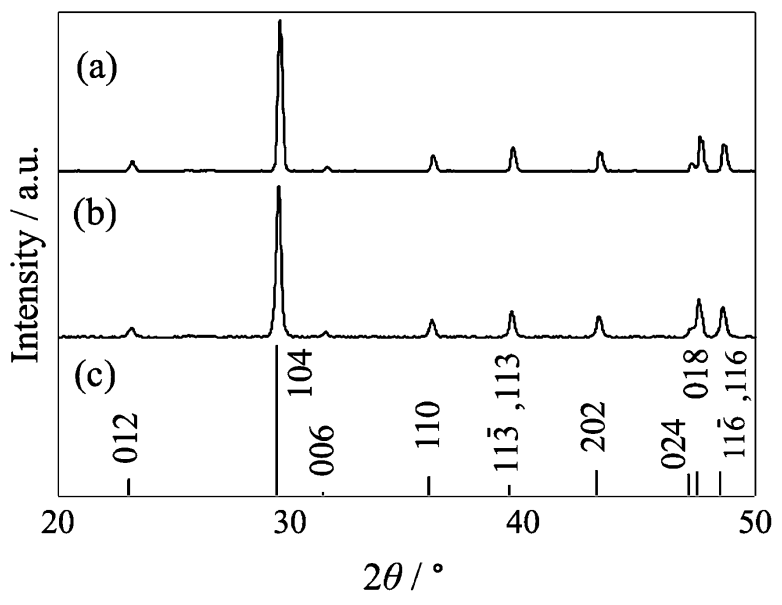

Fig. 3. XRD patterns of (a) $\mathrm{CaCO}_{3}$ and (b) scallop shell after $15 \mathrm{~h}$ suspension in an aqueous solution of $\mathrm{SrCl}_{2}\left(1.1 \mathrm{~g} / \mathrm{dm}^{3} \mathrm{Sr}^{2+}\right)$. (c) is calcite peaks. ${ }^{13)}$

of powder to $0.50 \mathrm{dm}^{3}$ (concentration of the powder 60 $\mathrm{g} / \mathrm{dm}^{3}$ ) of solution at $25^{\circ} \mathrm{C}$. At this high concentration, there was no significant difference between the $\mathrm{Sr}^{2+}$ removability over time of scallop shell powder and $\mathrm{CaCO}_{3}$.

\subsection{Sr present in the scallop shell powder}

Since the $\mathrm{Sr}^{2+}$ concentration in the aqueous solution was decreasing, we hypothesized that the removed $\mathrm{Sr}^{2+}$ was contained in the scallop shell powder. We therefore attempted to identify Sr compounds within the solids using $\mathrm{XRD}$, as shown in Fig. 3.

After suspension, the scallop shell powder had peaks at the same positions as $\mathrm{CaCO}_{3}$. However, we were unable to identify compounds containing $\mathrm{Sr}$ due to the detection limit of the laboratory XRD. Therefore, in order to investigate the presence of trace amounts of $\mathrm{Sr}$ compounds, we took measurements with XPS, which is capable of detecting Sr with higher sensitivity (Fig. 4).

Scallop shell was cut into squares weighing $3.0 \mathrm{~g}$ using a diamond cutter. This bulk scallop shell sample was added to $0.050 \mathrm{dm}^{3}$ of an aqueous solution of $\mathrm{SrCl}_{2}(1.1$ $\mathrm{g} / \mathrm{dm}^{3} \mathrm{Sr}^{2+}$ ) and left for 2 months. To ensure conductivity during XPS measurements, the sample was wrapped in a non-glossy aluminum wheel. The scallop shell has an additional $\mathrm{Sr}$ peak after $\mathrm{Sr}^{2+}$ removal, showing that it did contain Sr.

\subsection{Removal of low concentration $\mathrm{Sr}^{2+}$ by scallop shell}

Since a previous report mentioned in detail the mechanism of $\mathrm{Sr}^{2+}$ removal from an aqueous solution $\left(1.1 \mathrm{~g} / \mathrm{dm}^{3}\right.$ $\mathrm{Sr}^{2+}$ ), we decided to focus on a $\mathrm{Sr}^{2+}$ initial concentration of $0.010 \mathrm{~g} / \mathrm{dm}^{3}$, where there was a significant difference in the $\mathrm{Sr}^{2+}$ removability between scallop shell and the $\mathrm{CaCO}_{3}$. Figure 5 shows the change over time in the $\mathrm{Sr}^{2+}$ residual rate in a $\mathrm{SrCl}_{2}$ aqueous solution with a low initial concentration $\left(0.010 \mathrm{~g} / \mathrm{dm}^{3} \mathrm{Sr}^{2+}\right)$. The experiment was conducted by adding $3.0 \mathrm{~g}$ of powder to $0.050 \mathrm{dm}^{3}$ (con-
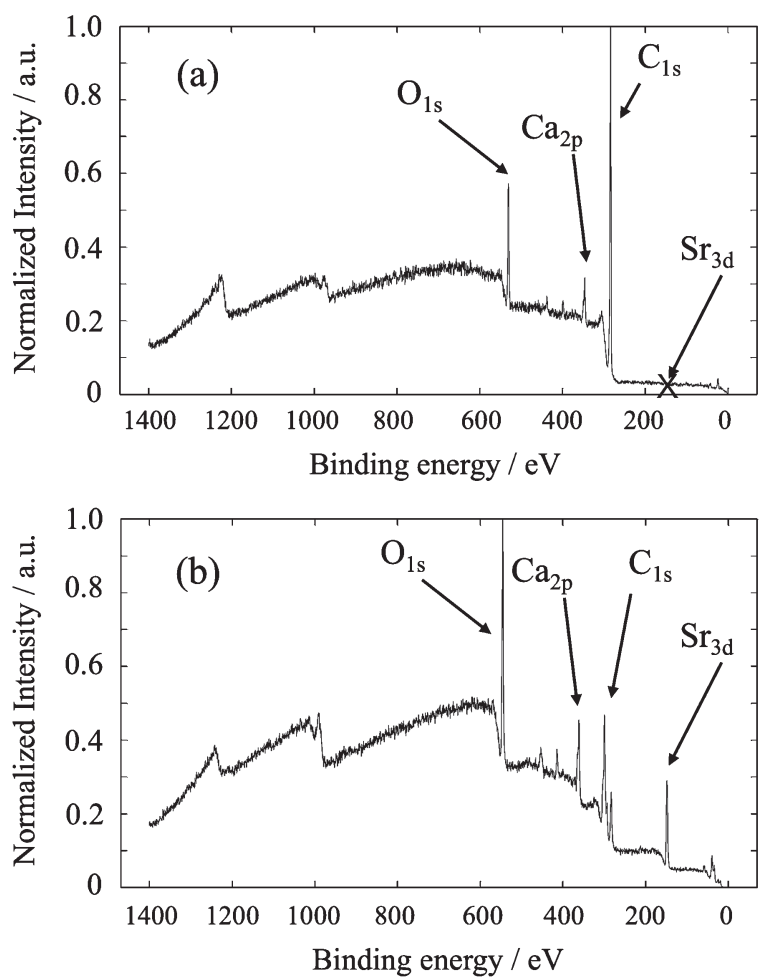

Fig. 4. XPS spectra of (a) original scallop shell and (b) after being immersed for 2 months in an aqueous solution of $\mathrm{SrCl}_{2}$ $\left(1.1 \mathrm{~g} / \mathrm{dm}^{3} \mathrm{Sr}^{2+}\right)$.

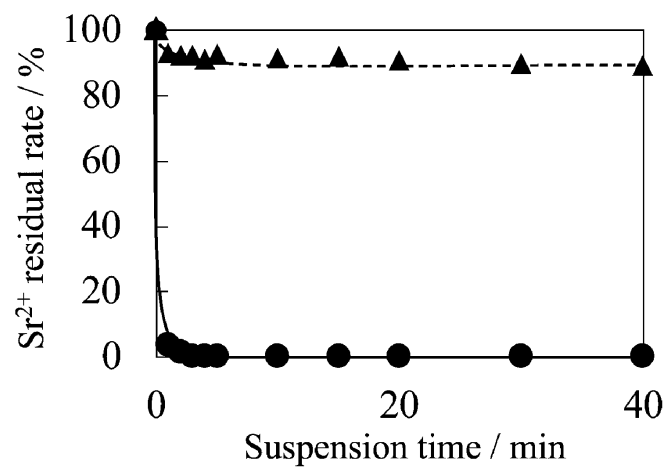

Fig. 5. Change of $\mathrm{Sr}^{2+}$ residual rate with time in suspension. ( $\boldsymbol{\Delta}$, a dotted line) $\mathrm{CaCO}_{3}$ and $(\boldsymbol{O}$, a solid line) scallop shell. Initial concentration of $\mathrm{Sr}^{2+} 0.010 \mathrm{~g} / \mathrm{dm}^{3}, 25^{\circ} \mathrm{C}$, concentration of the powder $60 \mathrm{~g} / \mathrm{dm}^{3}$.

centration of the powder $60 \mathrm{~g} / \mathrm{dm}^{3}$ ) of aqueous solution at $25^{\circ} \mathrm{C}$.

Within about 3 min of suspension, scallop shell powder was able to remove $\mathrm{Sr}^{2+}$ to below the detection limit of the AAS (saturated $\mathrm{Sr}^{2+}$ adsorption amount of scallop shell powder at $0.010 \mathrm{~g} / \mathrm{dm}^{3} \mathrm{Sr}^{2+}$ initial concentration is 0.35 $\mathrm{mg} / \mathrm{g}$ ). Despite the fact that there was no difference between the two powders at a high initial $\mathrm{Sr}^{2+}$ concentration $\left(1.1 \mathrm{~g} / \mathrm{dm}^{3}\right)$, the scallop shell powder demonstrated an entirely different $\mathrm{Sr}^{2+}$ removal capability to $\mathrm{CaCO}_{3}$ at this low initial $\mathrm{Sr}^{2+}$ concentration $\left(0.010 \mathrm{~g} / \mathrm{dm}^{3}\right)$. Therefore, we considered the possibility that composition of scallop shell powder and $\mathrm{CaCO}_{3}$ are different. 


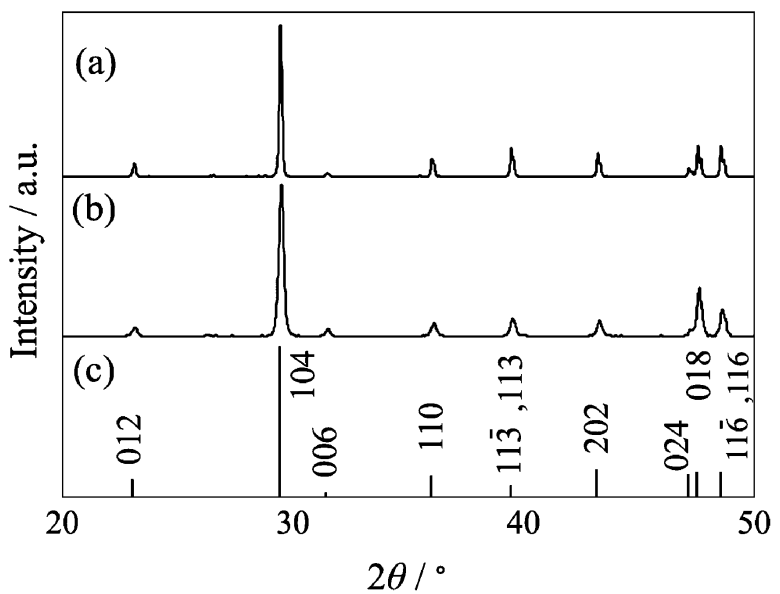

Fig. 6. XRD patterns of (a) $\mathrm{CaCO}_{3}$ and (b) scallop shell powder. (c) is calcite peaks. ${ }^{13)}$
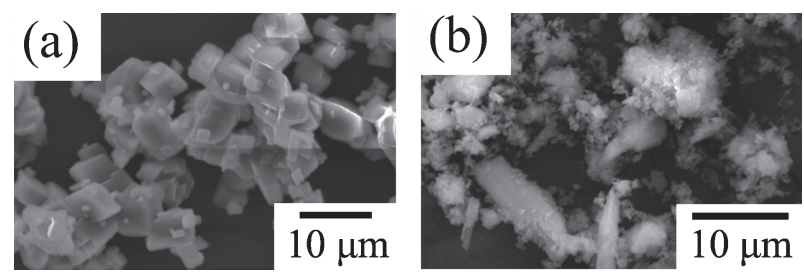

Fig. 7. SEM images of (a) $\mathrm{CaCO}_{3}$ and (b) scallop shell powder.

The results of XRD measurements of the scallop shell powder and the reagent $\mathrm{CaCO}_{3}$ are shown in Fig. 6.

The scallop shell powder was found to have peaks at the same positions as $\mathrm{CaCO}_{3}$. Thus, the crystal structure of the scallop shell powder and $\mathrm{CaCO}_{3}$ was the same. Therefore, we theorized that the difference in $\mathrm{Sr}^{2+}$ removability was attributable to the microstructure of the powder.

Figure 7 shows SEM observations of the microstructure of scallop shell powder had a large amount of long and narrow particles, whereas $\mathrm{CaCO}_{3}$ had a different particle shape like a cube. There were no other obvious differences; hence, we investigated the presence or absence of pores by measuring nitrogen adsorption and desorption.

Figure 8 shows the nitrogen adsorption-desorption isotherms of scallop shell powder and reagent $\mathrm{CaCO}_{3}$. The pre-treatment was carried out at $130^{\circ} \mathrm{C}$ for $2 \mathrm{~h}$ and the temperature at the time of nitrogen desorption was $77 \mathrm{~K}$. Hysteresis of the isotherm was observed only for scallop shell powder. According to the classification of international union of pure and applied chemistry, ${ }^{14)}$ the type of $\mathrm{H} 3$ loop is assumed that particles giving rise to slit-shaped pores. It is therefore presumed that the scallop shell powder has slit-shaped pores, and the $\mathrm{CaCO}_{3}$ has no pores. Hence, it was considered that the scallop shell powder may have a larger surface area than the reagent $\mathrm{CaCO}_{3}$.

The specific surface area is calculated by the BET method. Scallop shell powder had a specific surface area of $4.3 \mathrm{~m}^{2} / \mathrm{g}$, while that of $\mathrm{CaCO}_{3}$ was $0.14 \mathrm{~m}^{2} / \mathrm{g}$. Because the scallop shell powder has pores that are not present in $\mathrm{CaCO}_{3}$, and because the specific surface area of scallop
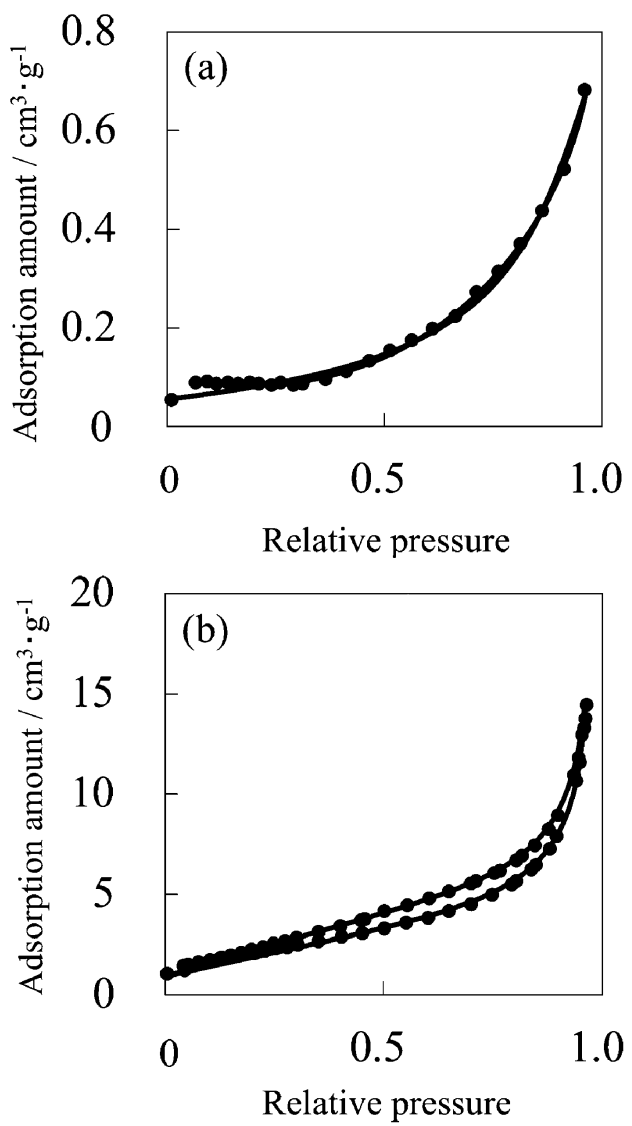

Fig. 8. Adsorption isotherm by the nitrogen adsorption method. (a) $\mathrm{CaCO}_{3}$, (b) scallop shell.

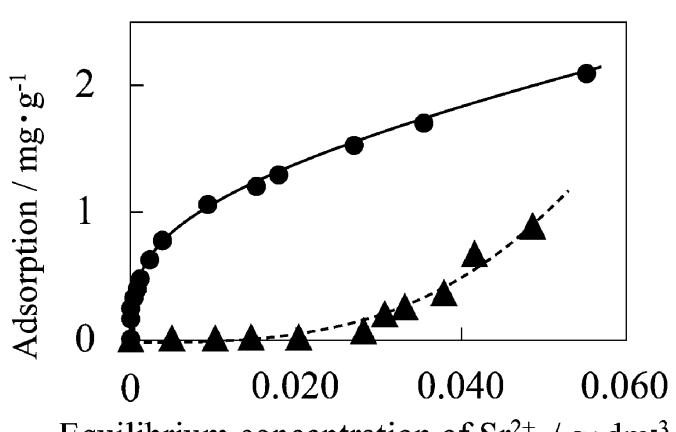

Equilibrium concentration of $\mathrm{Sr}^{2+} / \mathrm{g} \cdot \mathrm{dm}^{-3}$

Fig. 9. Adsorption isotherm in $\mathrm{Sr}^{2+}$ aqueous solution. $(\boldsymbol{A}, \mathrm{a}$ dotted line) $\mathrm{CaCO}_{3}$, (, a solid line) scallop shell. Initial concentration of $\mathrm{Sr}^{2+} 0.010$ to $0.10 \mathrm{~g} / \mathrm{dm}^{3}, 25^{\circ} \mathrm{C}$, concentration of the powder $60 \mathrm{~g} / \mathrm{dm}^{3}$.

shell powder is greater than $\mathrm{CaCO}_{3}$, the removal of $\mathrm{Sr}^{2+}$ by scallop shell powder may be through adsorption.

\subsection{Classification of $\mathrm{Sr}^{2+}$ removal by scallop shell powder}

The adsorption isotherm of scallop shell powder in an aqueous solution of $\mathrm{SrCl}_{2}$ is shown in Fig. 9. The $\mathrm{Sr}^{2+}$ concentration was regarded as equilibrium after suspension for $15 \mathrm{~h}$. The experiment was conducted by adding $3.0 \mathrm{~g}$ of powder to $0.050 \mathrm{dm}^{3}$ (concentration of the powder $\left.60 \mathrm{~g} / \mathrm{dm}^{3}\right)$ of an aqueous solution of $\mathrm{SrCl}_{2}\left(\mathrm{Sr}^{2+}\right.$ concen- 


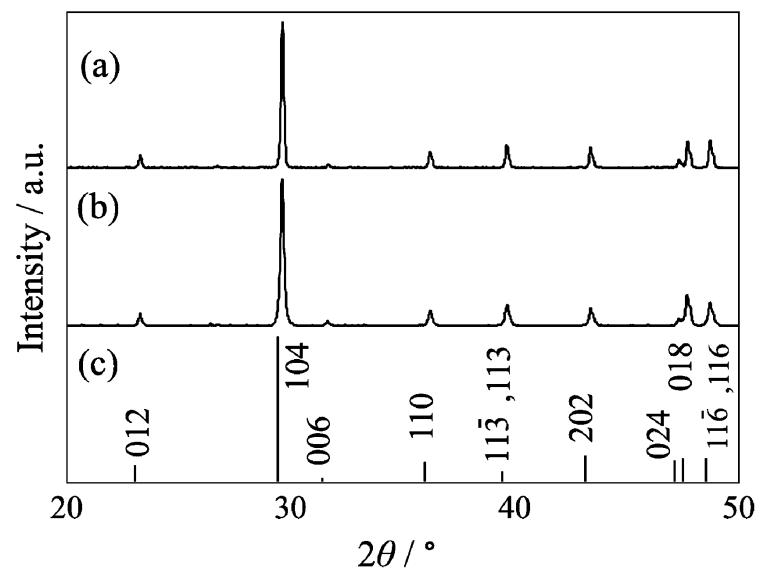

Fig. 10. XRD patterns of (a) $\mathrm{CaCO}_{3}$ and (b) scallop shell after $15 \mathrm{~h}$ suspension in an aqueous solution of $\mathrm{SrCl}_{2}\left(0.010 \mathrm{~g} / \mathrm{dm}^{3}\right.$ $\mathrm{Sr}^{2+}$ ). (c) is calcite peaks. ${ }^{13)}$

tration: 0.010 to $0.10 \mathrm{~g} / \mathrm{dm}^{3}$ ), at an aqueous solution temperature of $25^{\circ} \mathrm{C}$.

The isotherm curve for scallop shell powder took a convex upward shape, but for $\mathrm{CaCO}_{3}$ it was in the form of a downward convex shape. Generally, when the shape of the isotherm is upwardly convex, there is strong interaction between the adsorbent and the adsorbate, and a high possibility of chemisorption. Conversely, a downwardly convex curve implies that there is no interaction between the absorbent and the adsorbate, so it is not possible to say there has been an adsorption phenomenon. ${ }^{15)}$ Since the graph of scallop shell powder is in the shape of an upwardly convex curve, it is presumed that $\mathrm{Sr}^{2+}$ is removed by chemisorption. Since scallop shell powder is highly likely to chemically adsorb $\mathrm{Sr}^{2+}$, we tried to identify compounds containing Sr that formed on the surface of the scallop shell powder particles.

Figure 10 shows the results of using XRD to identify compounds in scallop shell powder that contain $\mathrm{Sr}$ after adsorption.

We measured the powders that were suspended in the aqueous solution of $\mathrm{SrCl}_{2}\left(\mathrm{Sr}^{2+}\right.$ concentration: 0.010 $\mathrm{g} / \mathrm{dm}^{3}$ ) for $15 \mathrm{~h}$ each, then filtered and dried. After suspension, the scallop shell powder had peaks at the same positions as for $\mathrm{CaCO}_{3}$, and we observed no peak attributable to the compound containing Sr. However, there is a possibility that a trace amount of $\mathrm{Sr}$ compound is present in scallop shell powder below the amount detectable by the laboratory XRD.

Therefore, we measured the powder adsorbed with $\mathrm{Sr}^{2+}$ by TOF-SIMS, which provides higher sensitivity (Fig. 11). The powders were suspended in an aqueous solution of $\mathrm{SrCl}_{2}\left(0.010 \mathrm{~g} / \mathrm{dm}^{3} \mathrm{Sr}^{2+}\right)$ for $15 \mathrm{~h}$, then filtered and dried. Since scallop shell naturally contains trace amounts of $\mathrm{Sr}$ which are present in the ocean, ${ }^{16)}$ in order to clarify whether or not $\mathrm{Sr}$ is adsorbed onto the scallop shell powder, it is necessary to compare the level of $\mathrm{Sr}$ in scallop shell powder before and after suspension.

The TOF-SIMS profile of scallop shell powder after suspension [Fig. 11(b)] is similar to that of the reagent $\mathrm{SrCl}_{2}$
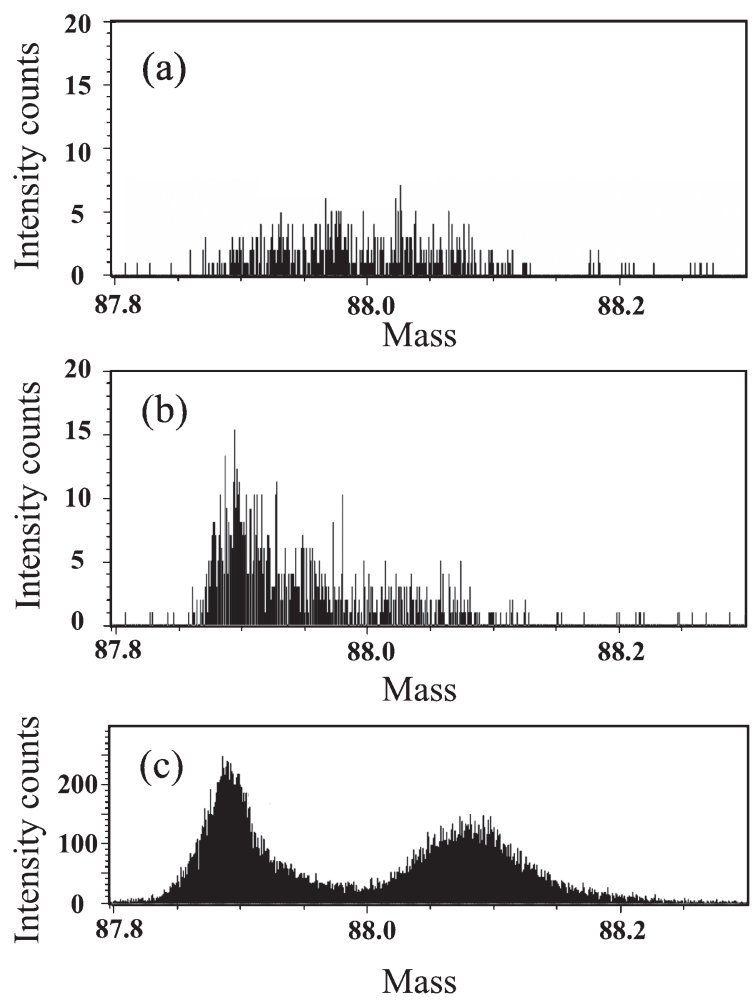

Fig. 11. Comparison of the Sr spectra of scallop shell powder (a) before and (b) after $\mathrm{Sr}^{2+}$ adsorption. (c) $\mathrm{Sr}$ spectrum of regent $\mathrm{SrCl}_{2}$.

[Fig. 11(c)] but differs from the profile before suspension [Fig. 11(a)]. Thus, the $\mathrm{Sr}$ contained in the suspended scallop shell powder is derived from $\mathrm{SrCl}_{2}$.

\section{Conclusions}

Although $\mathrm{Sr}^{2+}$ removal via scallop shell powder is similar to that via $\mathrm{CaCO}_{3}$ at a high initial $\mathrm{Sr}^{2+}$ concentration $\left(\geq 0.50 \mathrm{~g} / \mathrm{dm}^{3}\right)$, a clear difference in $\mathrm{Sr}^{2+}$ removability appears with a low initial concentration $\left(<0.50 \mathrm{~g} / \mathrm{dm}^{3}\right)$, where scallop shell powder was superior. The scallop shell powder was found to have slit-shaped pores and a specific surface area of $4.3 \mathrm{~m}^{2} / \mathrm{g}$. Furthermore, the removed $\mathrm{Sr}^{2+}$ was found to be present on the surface of the scallop shell powder by chemisorption.

Acknowledgement The authors are thankful to Dr. Yoshitsugu Akiyama and Mr. Ross Cooper of Liberal Arts in Oshamambe, Faculty of Industrial Science and Technology, Tokyo University of Science. We also thankful to Dr. Naoto Kitamura and Dr. Naoya Ishida of the Department of Pure and Applied Chemistry, Graduate School of Science and Technology, Tokyo University of Science. We are also thankful to Hokusho Fisheries and the Oshamambe Fishery Cooperative Association.

\section{References}

1) Tokyo Electric Power Company Holdings Corporation "Storage situation of accumulated water", Tokyo Electric Power Company Holdings Corporation, Tokyo 
(2018) pp. 1-2.

2) L. Zhang, J. Wei, X. Zhao, F. Li, F. Jiang and M. Zhang, Chem. Eng. J., 267, 245-252 (2015).

3) K. Mori, M. Iwasaki, H. Mimura and H. Kanda, J. Ion Exch., 26, 34-40 (2015).

4) X. Li, W. Mu, X. Xie, B. Liu, H. Tang, G. Zhou, H. Wei, Y. Jian and S. Luo, J. Hazard. Mater., 264, 386-394 (2014).

5) N. Koyama, S. Okuda and K. Sasaya, Expected Mater. Future, 2, 43-51 (2002).

6) S. Yamanaka, A. Suzuma, T. Fujimoto and Y. Kuga, J. Nanopart. Res., 15, 1573-1580 (2013).

7) S. Yamanaka, K. Magara, Y. Hirabayashi, T. Fujimoto and Y. Kuga, J. Soc. Powder Technol., Jpn., 51, 400406 (2014).

8) A. Suzuma, Y. Kondo, T. Fujimoto and Y. Kuga, SCEJ 41st Autumn Meeting, Sep. 16-18, Hiroshima, Japan (2009) p. 403.

9) I. Naruse, K. Nishimura and K. Ohtake, Kagaku Kogaku
Ronbunshu, 21, 904-909 (1995).

10) T. Murakami, K. Saito and I. Naruse, J. Jpn. Inst. Energy, 79, 1070-1077 (2000).

11) K. Yoshimura and H. Shiomi, J. Soc. Mat. Sci., Jpn., 62, 373-376 (2013).

12) F. Mihara, K. Takeuchi, Y. Idemoto and Y. Kogo, J. Soc. Inorg. Mater., Jpn., 25, 87-91 (2018).

13) H. E. Swanson and R. K. Fuyat, "Standard X-ray Diffraction Powder Patterns, Volume II", National Bureau of Standards, Washington, D.C. (1953) pp. 51-54.

14) K. S. W. Sing, D. H. Everett, R. A. W. Haul, L. Moscou, R. A. Pierotti, J. Rouquérol and T. Siemieniewska, Pure Appl. Chem., 57, 603-619 (1985).

15) S. Kondo, T. Ishikawa and I. Abe, "Science of adsorption second edition", MARUZEN-YUSHODO, Tokyo (2005) pp. 56-57, 97-98.

16) K. Okoshi, "Sea mineralogy_Relationship with and use of living organisms", SEIZANDO-SHOTEN, Tokyo (2007) pp. 62-65. 